\title{
The Impact of Urban Expansion on Physical Environment in Debre Markos Town, Ethiopia
}

\author{
Temesgen Mekuriaw ${ }^{1 *} \quad$ Prof. Dr. Huseyin Gokcekus ${ }^{2}$ \\ 1.Lecturer, Department of Hydraulic and Water Resources Engineering Debre Tabor university, Debre Tabor, \\ Ethiopia \\ 2.Faculty of Civil and Environmental Engineering Near East University Nicosia/ North Cyprus
}

\begin{abstract}
This study aims to investigate the major consequence of urban expansion in urban areas particularly in Debre Markos town with review of relevant literatures. The finding of the paper was presented by using charts, table, graphs, and figures. This study shows that Debre Markos town is one of Ethiopian urban settings experiencing unique rate of urbanization through expansion. The findings of the study showed that the trend of urban expansion increase from time to time mostly forest and cultivated land have been changed into different urban development uses such as residential, industrial, and commercial and other various institutions. The central factors that contribute to rapid expansion of the town are discussed with detail interpretation of the data. The adverse effects of rapid urban expansion on the natural (physical) environment due to land use change and in the town and nearby areas discussed in detail. Hence, the objective of this study was to assess the consequence of horizontal urban expansion on physical environment but for the future study it is necessary to focus on social and economic impacts.
\end{abstract}

Keywords: urbanization, urban expansion, environmental degradation, environment,

DOI: $10.7176 / C E R / 11-5-03$

Publication date:June $30^{\text {th }} 2019$

\section{INTRODUCTION}

In recent years, cities all over the world have experienced rapid growth because of the rapid increase in world population and the irreversible flow of people from rural to urban areas. The urban population of the world has grown rapidly from 751 million in 1950 to 4.2 billion in 2018.Today, $55 \%$ of the world's population lives in urban regions; this ratio is expected to increase to $68 \%$ by 2050 . Projections demonstrate that urbanization, the gradual shift in residence of the human population from rural to urban areas, combined with the overall growth of the world's population could add another 2.5 billion individuals to urban zones by 2050 , with nearly $90 \%$ of this expansion occurring in Asia and Africa, according to a new United Nations (2018). In the developed nations of Europe and North America, urbanization has been an outcome of industrialization and financial improvement. By contrast, in the developing nations of Latin America, Africa and Asia it has occurred due to consequence of demographic phenomenon (William, 1983; Achamyeleh G., 2014).

The rate of urbanization in Ethiopia is one of the quickest in Africa. The normal yearly rate of development from 1960-1991 was 4.8 percent and this figure developed to 5.8 percent per-annum from 1991-2000. Likewise, the yearly development rate from $2000-2010$ was 5.5 percent and abatements to 4.73 in 2017 . This rate of development puts Ethiopia among the 23 quickly urbanizing nations of the world. According to Redman and Jones, 2004 and Cohen, 2006, as cited by Dejene (2011) and Henok (2014), the principal reasons for raising the level of urbanization and city growth are population growth, rural-urban migration, and geographical expansion of urban areas through annexation and transformation and re-classification of rural village into small urban settlements. Rapid pass of urbanization is passing major challenge in front of cities in developing countries. One of the significant difficulties is urban extension which is an inescapable result of urbanization process (Firew, 2010; Hussien, 2013; Debela et al., 2016).

Many of Ethiopian cities and/ or towns have experienced rapid horizontal expansion; but which was not properly controlled by appropriate planning intervention, weak implementation capacity, weak institutional capacity as well as lack of good governance in cities or towns. As such uncontrolled rapid horizontal expansion of cities/towns towards the agricultural communities resulted in additional social, economic, environmental and political problems (Eyasu, 2007; Demel, 2011; Firew, 2010; Mulu W., 2016; Debela et al., 2016;).

Debre Markos town today has faced a problem in relation to natural resource and the environment which are caused by urban expansion. Among others, the conversion of farm land and forest area in to different urban land uses, such as residential, commercial land and other activities are the main ones. With regard to the settlement pattern of the town, it has more of a linear settlement form. The neighborhoods are grouped and jumping large plots of land. Because of the present physical expansion of the town, various types of vegetation, agricultural lands, wetlands and grasslands are converted into urban land uses (Ziena L., 2017; Tigezew, 2014).

Deforestation has also been taking place at alarming rate due to residential and other alternative investment uses. From 1998 up to 2017 above 4850 hectare of agricultural land converted to urban uses. At the margin of the 
town, mining (such as stone excavation) for construction purposes has also been taking and exerting various adverse impacts on the environment (Girma, 2009; Tigezew, 2014; Ziena, 2017). The recent population growth and the dynamically changing economic activities resulted in reduce natural resource stocks at the side-line of the town. In light of the above discussion this study intends to investigate the major impacts of urban expansion on the environment the town of Debre Markos.

\subsection{Objectives of the Study}

General intention of this study is to evaluate the effect of urban expansion on the environment in Debre Markos town. Specific Objectives of the paper was undertaken with the aim of achieving the following specific objectives:

i. To examine the trend of urban expansion of Debre Markos town.

ii. To identify the major causes that contributed to rapid urban expansion of the town

iii. To assess the impacts of urban expansion on environment (mainly on cultivated land, wetland, forest land and land degradation).

\section{RELATED LITERATURES}

\subsection{Concepts of Urban Expansion}

Urban expansion is unplanned, unwanted spreading of urban development in to areas adjoining the edges of a city. Urban sprawl is the physical example of low-thickness development of huge urban territories under in to the encompassing farming zones. Sprawl lies in advances of the principal of urban growth and implies little planning control of land subdivision. Development is putting, scattered and strong out, with a tendency to discontinuity because it leaps flows over some areas, leaving agricultural enclaves. Urban expansion is a dynamic element, subject to different sorts of activities, for example, physical, social and economical. These forces are mainly responsible for rapid pass of urbanization of human settlement. It is a continuous process which is not mainly associated with industrialization but a combination of all factors underlying the process of economic growth and social change. Rapid expansion of urbanization is passing major opportunities' and challenge in front of cities in developing countries. One of the major challenges is an inevitable outcome of urbanization process (Sonor, 2008; Getahun,2017). As the urbanization rate is increasing rapidly, urban centers horizontally expand and consume more land. Since demographic pressure exerted on natural resource base has exceeded its carrying capacity, it is quite natural to call it as one of the most formidable challenge for attainment of sustainable development (Tersa, 1990). Urban Expansion is mostly uncontrolled that one often sees overcrowding (slum and shanties) and extended unplanned settlement with acute shortage of infrastructure in one part and unutilized or partially developed vacant land on the other part (Feyera, 2005; Adem, 2010; Yohannis, 2013).

\subsection{Trends of Urban Expansion}

\subsubsection{Urban Expansion in the World}

Urbanization is not a modern phenomenon; it was occurring since about 5000 B.C. The level of urbanization can be measured by the ratio of population live in urban to the total population which has been increasing in a given year. After the Second World War urbanization took place rapidly all over the world. Urbanization levels were high in developed nations of Europe, North America and Oceania, with more than 50\% of the population living in the urban areas. (United Nations, 2000; cited by Hussien, 2013)

The urban population of the world has grown rapidly from 751 million in 1950 to 4.2 billion in 2018 . Currently, 55 percent of the world population lives in cities and suburbs, this ratio is estimated to grow $68 \%$ by 2050. Estimations demonstrate urbanization; the gradual change in habitation of the people from rural to urban areas, with joint progress of population growth of the globe could add 2.5 billion individuals to urban zones by 2050 , with nearly $90 \%$ of this expansion occurring in developing countries of Africa and Asia (UN, 2018). Today, the most urbanized districts incorporate Northern America (82\%), Latin America and the Caribbean (78\%), Europe (74\%) and Oceania (67\%). The level of urbanization in Asia is now approximating 50\%. In contrast, Africa remains mostly rural, with $43 \%$ of its population living in urban areas. 


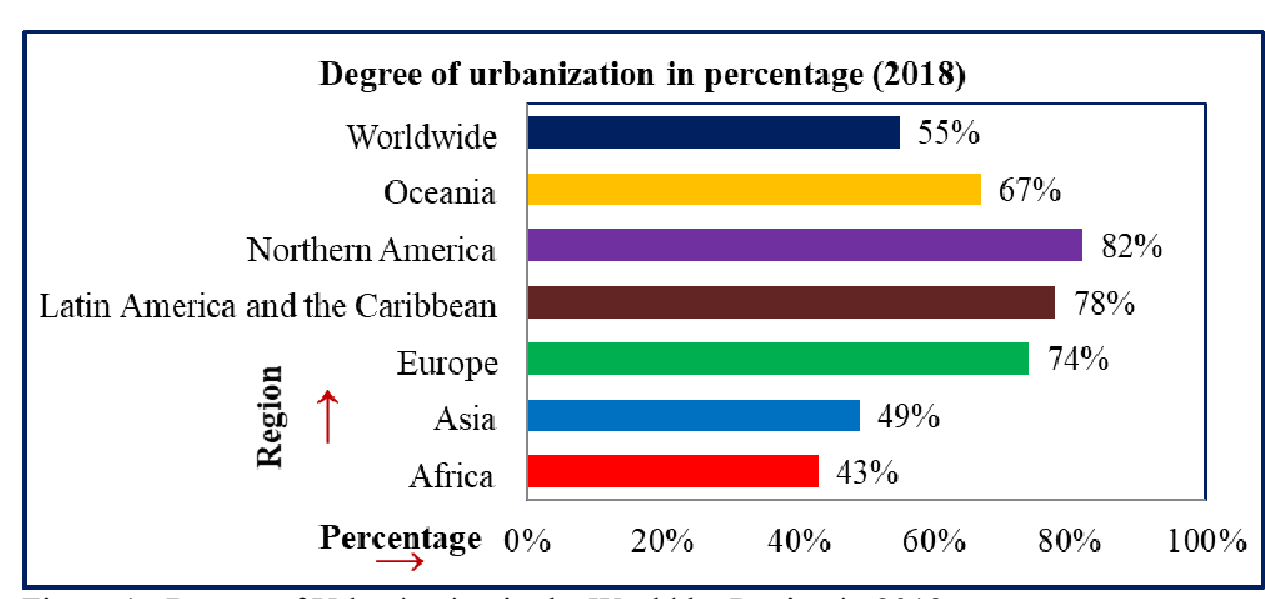

Figure 1: Degree of Urbanization in the World by Region in 2018

Source: computed from data of Population Reference Bureau $(2018$

In developing countries, the growth of cities is dynamic, diverse, disordered, and increasingly space extensive. Pre-urban zones regularly need clear controls and managerial expert over land utilize. They endure a portion of the most exceedingly awful results of urban development, including population, rapid social change, poverty, land use changes and degradation of natural resources. With respect to trends, it is estimated that $93 \%$ of urban growth will occur in developing nations with $90 \%$ of urban growth occurring in Asia and Africa. Particularly, currently African average level of urbanization is $40 \%$ and Sub-Saharan Africa is currently about $30 \%$ urbanized (United Nations 2018), while the Ethiopia's is 23\%. This rate of growth puts Ethiopia among the 23 rapidly urbanizing countries of the world (Firew, 2010).

\subsubsection{Urban Expansion in Ethiopia}

In the early $1960 \mathrm{~s}$, urbanization rate in the country was 6.4 percent. According to the 2000 National Population Census, the country's population reached 66537331 out of which only 9731656 or $14.6 \%$ constituted urban population. Despite these facts, in Ethiopia there are indicators of accelerated urban expansion. In 2018, the total population of the country reached 107,534,882, of which $20.6 \%$ were urban inhabitants (http://www.worldometers.info).

As indicated by environmental change and security program report (2004), urbanization is not yet a major problem in Ethiopia. However, the rate of population growth in urban areas is high, the country currently witnessing one of the fastest rates of urban growth in the world, namely an average $5 \%$ per annum. It is stated that urban development happens to the detriment of profitable agrarian land and the destruction of forests. If the current pace of industrialization continuous, the environmental damage and impact on agricultural production will be severe. In addition, infrastructure provision for urban expansion area is almost non-existent in the country services such as piped water, sanitation; sewerage, road etc. are not adequately available. Generally, there is a mismatch between government capacity and the needs of the community with regard to infrastructure provision in pre-urban areas than in the core cities.

The major causes of urban expansion or sprawl are a reaction of various arrangements of financial, social and political powers to the physical geography of a territory. The forces or factors include population growth, migration, increasing housing in come, fragmented metropolitan governments, and patterns of infrastructure investments, and the construction of roads. The expansion trend of Ethiopia is similar to developing countries expansion trend. The causes are rapid population growth of urban residents and in-migration due to pulling factors like employment opportunity, provision of social infrastructure, transportation facility aggravate the expansion of Ethiopian urban centers (Debela, 2016; Getahun, 2017; Paulos,2017).

\subsection{Impacts of Urban Expansion in Ethiopia}

According to NUPI (1996), the rapid population growth of cities and towns in Ethiopia creates a huge demand and pressure on urban land use, there is a need of urban land for manufacturing, commence, service, residential, recreation and other activities. The urban land demand is unsatisfied mainly due to the problems and constraints in the land allocation system. The cumulative impact of urban expansion in Ethiopia includes uneconomic use of land, unnecessary conflict of boundary between adjacent land owners, illegal land holding of public green buffer zones, and other unoccupied plot and left-over spaces by individuals and in some belongings and organizations. According to Berke (2006), Debela (2016) and Paulos (2017), the urban expansion and associated activities degrade environmental resource, such as surface water and growth wave, air quality and landscape aesthetic and destroy wild life habitats. The negative effects of urban expansion are most clearly evidenced by increased demand for land to accommodate each new increment of population growth.

Urbanization and urban growth are considered as a modern way of life and centers of varieties of human 
opportunities which all can highly contribute to socio-economic growth and development. However, as Tegegne (1996) and Ahlem (2017) argues, horizontal expansion of urban areas in Ethiopia causes a number of socioeconomic problems including tenure right violation. Urban expansion in Ethiopia impedes the livelihood elements and strategies of peri-urban communities and hence leads them in to vulnerability shocks.

Urbanization and urban growth of Ethiopia is dominated by a primate city. The 1994 Population and Housing Census demonstrate that Addis Ababa has 28.4 percent of the National urban population and is twelve times larger than the second largest city, Dire Dawa. This resulted in physical expansion of the city to the margin affect the ecosystem elements like the environment. A rapid and unplanned expansion and commercial development, along with population pressure, affects the natural environment with time. At present the forests of Addis Ababa are nearly changed to urban living spaces accommodating high population because of a high rate of provincial urban movement. Furthermore, industrialization within the urban areas and conversion of different land use within the city and the surrounding areas has caused the rapid depletion of existing tree cover during the past 100 years (Hancock, 1995). Generally, Changes in land use from rural to urban activities affects the physical form of environment as well as economic and social features of peri-urban interface. The agricultural land is an important source of new land for industry and service sectors. Yet, it can have adverse effects on displaced households in terms of livelihood disruption, and social and cultural consequences (DFID, 1999).

\section{STUDY AREA}

\subsection{Historical Background of the Town}

Debre Markos town was founded in 1852 by Dejazmach Tedla Gualu who was the then administrator of the town. Its name was initially called Menkorer. The name of the town was changed to Debre Markos when due to the establishment of Saint Markos church, King Tekle haimanot who came to power in 1879 proclaimed that the town shall be named Debre Markos instead of Menkorer. During its founding the total extent of the area was 272 hectares. Until 1995, the town was the administrative city of the province of Gojjam and currently served as the capital city of East Gojjam zone. The town has a structure plan which was prepared in 2009. Despite old age of the town, the socio-economic statuses of the citizens as well as infrastructural developments in the area were almost paused for a number of decades. But nowadays, motivated by the liberalized free market economy and other motivating instruments by the local government, the socio-economic status of the society is showing a considerable progress (Kalkidan, 2007; Abebaw,2017; Ziena,2017).

\subsection{Geographical Location}

Debre Markos town is located in the North- west of the capital city of the Federal Democratic Republic of Ethiopia, Addis Ababa at a distance of $300 \mathrm{Km}$ and $265 \mathrm{~km}$ to the capital of Amhara Nation Regional State Bahir Dar. Specifically, it is located in the Amhara regional state, East Gojjam zone. The geographical location of the study area is located between $10^{\circ} 17^{\prime} 00^{\prime \prime}$ to $10^{\circ} 21^{\prime} 30^{\prime \prime} \mathrm{N}$ Latitudes and $37^{\circ} 42^{\prime} 00^{\prime \prime}$ to $37^{\circ} 45^{\prime} 30^{\prime \prime} \mathrm{E}$ longitudes and its elevation ranges in altitude from 2350-2500 meters above the sea level ( (DMTID, 2011).

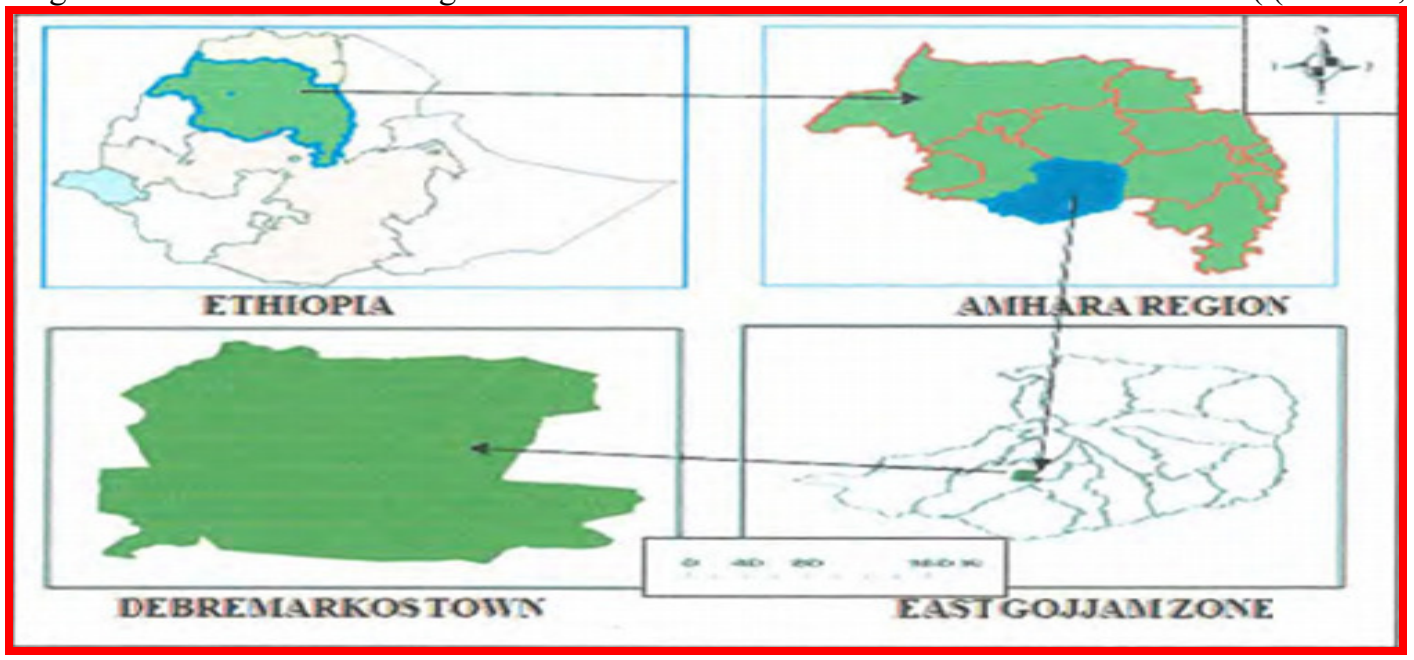

Figure 2: Location of Debre Markos town

Source: Debre Markos town municipality report, 2009 and Tigezew Lamesgen, 2014

\subsection{Topography}

The fundamental characteristic limitations for the physical development of the Debre Markos town are hills, swamps, streams and timberlands with a slope ranging between 2-10\%; while the synthetic imperatives are illicit settlements and urban rustic limit clashes. The area covered by Debre Markos town is not much suitable for 
urban development. This is mainly because the town is dissected by three swampy areas and to some extent by gullies, ridges and escarpments. In addition, the town is drained by three rivers: Wuseta, Wutrin and Abahim that flow to the south but in different directions. For instance, Wutrin drains the Western part of the town, while Wuseta drains the Eastern part of the town. Particularly the swampy area of Wutrin is the major source of water supply. Overall, the swampy areas along these riverbanks are main sources of grazing land for the town and its hinterland (NUPI, 2001 cited by Mulualem: 2009; Ziena, 2017).

\subsection{Population}

The number of inhabitants in the town is 62,469. Disaggregated by sex, 29,901(47.8\%) were males and 32,568 $(52.2 \%)$ females (CSA, 2007). The population growth rate at low variant was $2.4 \%$, while household size in the town is on average 3.2. According to CSA (2013), the majority of the urbanites worshiped Ethiopian Orthodox Tewahido church. $97 \%$ of the inhabitants are speakers of Amharic language. The remaining $3 \%$ of the inhabitants are speakers of Tigrigna, Agew and Afaan Oromo (EGFEDD, 2012; Debre Markos Town Administration, 2016).

\subsection{Data}

In an effort to make this research work more legitimate and admirable, appropriate secondary sources significant to the study were used. Consequently, official data and annual reports available in urban development executing agencies' were the key sources of secondary data for this study. Moreover, different written documents both published and unpublished- books, CSA, government, non-government documents, journals and research works in relation to the issue under consideration; government policy and strategy were reviewed to supplement the study as well as to review the overall trend and impact of urban expansion in the study area. The quantitative data which shows the population, land use and area of the town in percentage as well as the numerical data were analyzed interpreted in tabular and graphical forms. Qualitative data that shows the trend, status, challenges and perspectives of the urban expansion interpreted and explained with the support of the quantitative data.

\section{Result and Discussion}

\subsection{Trend of Urban Expansion in the town}

\subsubsection{Trends of Urban Land Use Planning and Settlement}

Debre Markos is one of the oldest towns that found in Amhara region. The first Master plan of the town was prepared by Italian in 1967 and later in 1992 by the Ministry of Urban Development and Housing (NUPI, 1998). Up on the foundation of Debre Markos, the town was divided into different sub neighborhood settlements. The centers of the settlements were occupied by major chiefs. After the down fall of Emperor Haile Selassie, all these neighborhood villages' names changed into a numbering system. Until 2005, the town had 7 kebeles. In general, these villages were fragmented independently in different directions of the town and the major land is used for agricultural purpose by feudal lords.

Since 2009, the town has expanded by including 13 rural kebeles which surround the town. These kebeles are Wonka from north, Dalgaw, Achira, and Yebo from south east, Chemoga from south, Yebragie from north, Endimata from east and Yemeka from west. The radius of the town was five kilometers at an average before these rural kebeles were incorporated to the town. But after the inclusions of these rural kebeles to the town, the radius was increased to about 10 kilometers. 


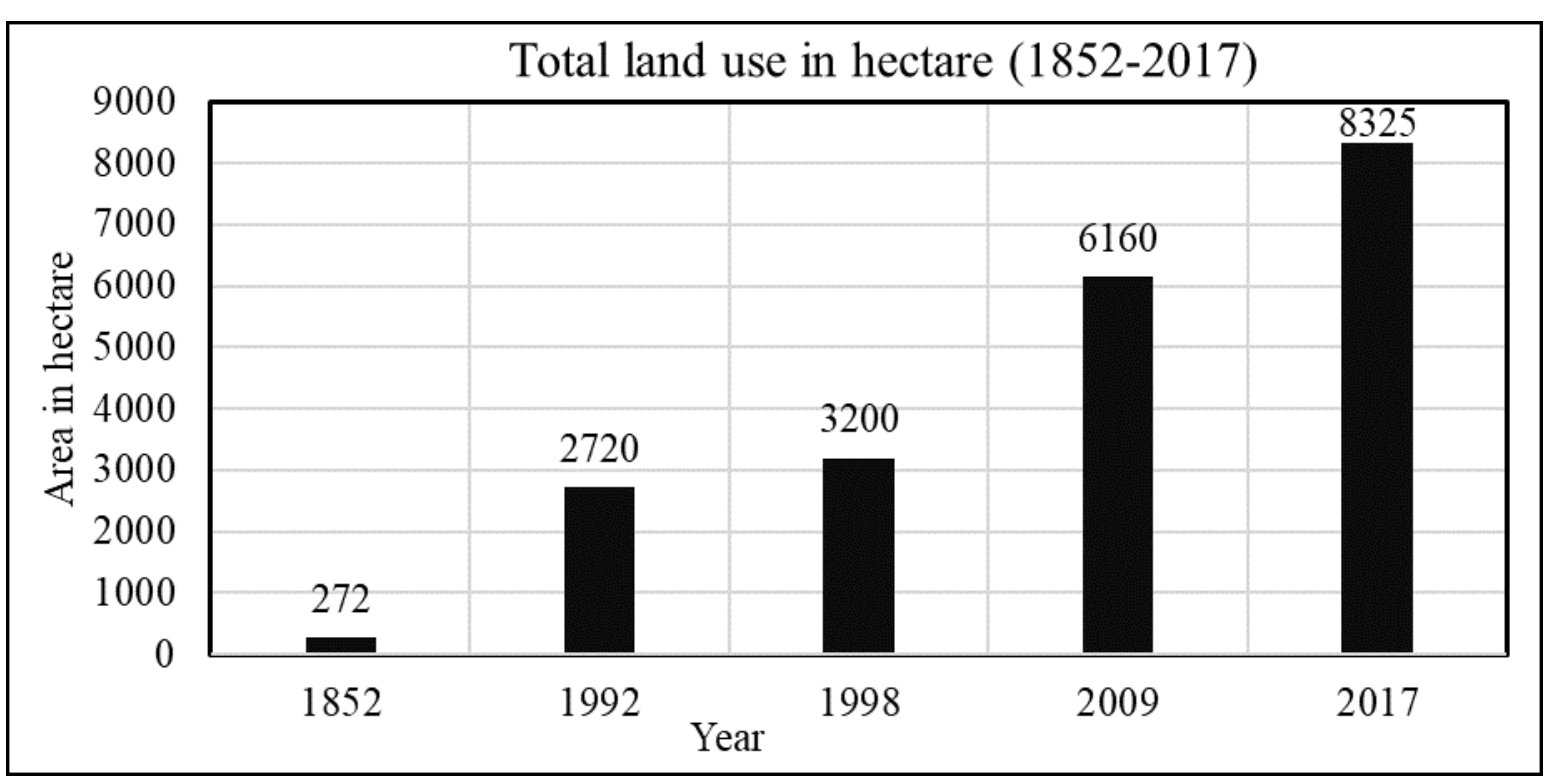

Figure 3. Trends of area expansion of Debre Markos town (in hectare)

Source: Computed from Debre Markos Municipality report, 2017

The past land use system of the town also contributes to the present fragmentation and linear expansion of the town. The delivery of land with large plot size without considering their land requirement for residential, commercial, governmental and non-governmental organization and outdated ownership of land in the form of live hold has contributed to the present outward expansion of the town. Up to now, development infill in the urban centers has not implemented in organized manner. Rather, cultivated lands, farm lands and green areas at the margin have been provided for new settlers for residential purpose. In addition to this, occupancy of vast areas and further expansion by few governmental and non-governmental organizations has contributed to the present horizontal expansion of the town.

\subsubsection{Trends of Urban Land Uses in the Town from 1998-2017}

As shown in table 1, among the major land use types, built up area took the lion share and this implies that there was high percentage of built up areas. The built up area included the residential, administration, commerce, social service, industries, transport and road land uses.

As shown from table lout of the total land use proposed, the residential use has covered 2733.4 ha (44.3\%), a reserved area has covered about 772 ha $(12.5 \%)$, commercial areas 723 ha $(11.7 \%)$ and administration areas has covered 61.1 ha $(0.9 \%)$. Out of the 2009 land use types, the residential land has taken the lion share $(44.3 \%)$ and this implies there have been a high percentage of land use for residential.

Table 2: Trends of land use change between the 1998 and 2017.

\begin{tabular}{|c|c|c|c|c|c|c|c|}
\hline \multirow{3}{*}{ no. } & \multirow{3}{*}{ Land Use type } & \multicolumn{6}{|c|}{ Year } \\
\hline & & \multicolumn{2}{|l|}{1998} & \multicolumn{2}{|l|}{2009} & \multicolumn{2}{|l|}{2017} \\
\hline & & Area & percentage & Area & Percentage & Area & Percentage \\
\hline 1 & Residence & 779.2 & 23.34 & 2733.4 & 44.3 & 4863.5 & 58.42 \\
\hline 2 & Administration & 27.2 & 0.85 & 723 & 11.7 & 825.4 & 9.91 \\
\hline 3 & Commercial & 108.6 & 3.39 & 542.4 & 8.8 & 686.2 & 8.24 \\
\hline 4 & Service & 281.7 & 8.8 & 61.1 & 0.9 & 15.2 & 0.18 \\
\hline 5 & Industrial & 2.1 & 0.06 & 137 & 2.2 & 205.5 & 2.47 \\
\hline 6 & Recreation & 88.7 & 2.77 & 362 & 5.8 & 411.13 & 4.94 \\
\hline 7 & Transportation & 267.4 & 8.35 & 220 & 3.5 & 234.6 & 2.82 \\
\hline 8 & Forest & 550 & 17.18 & 291.2 & 4.7 & 156.5 & 1.88 \\
\hline 9 & Special Area & 215.9 & 6.7 & 772 & 12.5 & 414.15 & 4.97 \\
\hline 10 & Urban Agriculture & 879.4 & 27.48 & 317.9 & 5.1 & 512.82 & 6.16 \\
\hline Tota & & 3200 & 100 & 6160 & 100 & 8325 & 100 \\
\hline
\end{tabular}

Source: computed from Debre Markos town master plan (2009) and municipality report (2017)

As shown on the above table the land use changed from the 1998 to 2017, all land uses show an increment by more than $50 \%$ except forest and agriculture land. During 18 years' period about 5125 hectares of land was included to urban land use. Among those land uses, residential took the lion share, indicating that the demand for housing increased whereas the demand for agricultural and forest land coverage decreased.

Generally, the demand for the built-up cover (residence, commerce, administration, services, manufacturing 
and industries, transport and road land uses) have been increasing from time to time than the forest, recreational and agricultural land use. Robert (2005) also confirmed that the built-up area of developing-country's cities will increase to more than 600,000 square kilometers by 2030. In other words, by 2030 these cities are expected triple their land area, with every new resident converting, on average 160 square meters of non-urban to urban land.

\subsubsection{Direction of Expansion of the Town}

Debre Markos has natural and manmade constraints that forced the town to develop in fragmented and dispersed urban pattern. From physical observation, the town's expansion direction is not only in the north part of the town as the previous plan had indicated. But in reality, there are expansions to the north-western, south, south-eastern and eastern directions following the main roads. According to Debre Markos 2009 structural plan, the expansion areas of the town were located in different directions within a walking distance from the main arterial roads. The main expansion area was a large tract of land situated in the northern north, western and southern edges of the town between Abma Mariam (kebele03) and Bahirdar roads (kebele 04) and Daligaw. In addition to this area, the two important housing areas that would have significance in shaping the urban pattern of the town were located left and the right side of the Debre Markos university road. The town generally expands horizontally year to year like other fastest growing cities of the country. When one sees the entire area of the town, it shows a scattered development both urban and rural characteristics.

\subsection{Causes of Urban Expansion in Debre Markos}

Among others, the rapid population growth of urban residents and migration due to pulling factors like employment opportunity, provision of social infrastructure, and transportation facility aggravated the expansion of Ethiopian urban centers (NUPI, 1998). Similarly, the causes for Debre Markos town expansion are population growth, availability of different infrastructure, absence of land information systems (LIS), and topography. These are further discussed below.

\subsubsection{Demographic Factors}

The expansion of Debre Markos town is at the expense of agricultural and forest land. The urban expansion is highly associated with population growth of the town. In 1967 the town population was 21536; and the figure has been observed to increases 49297 during the year 1994. According to CSA (2010) estimation/forecast of the 2018, the town's population growth would have reached 111313.

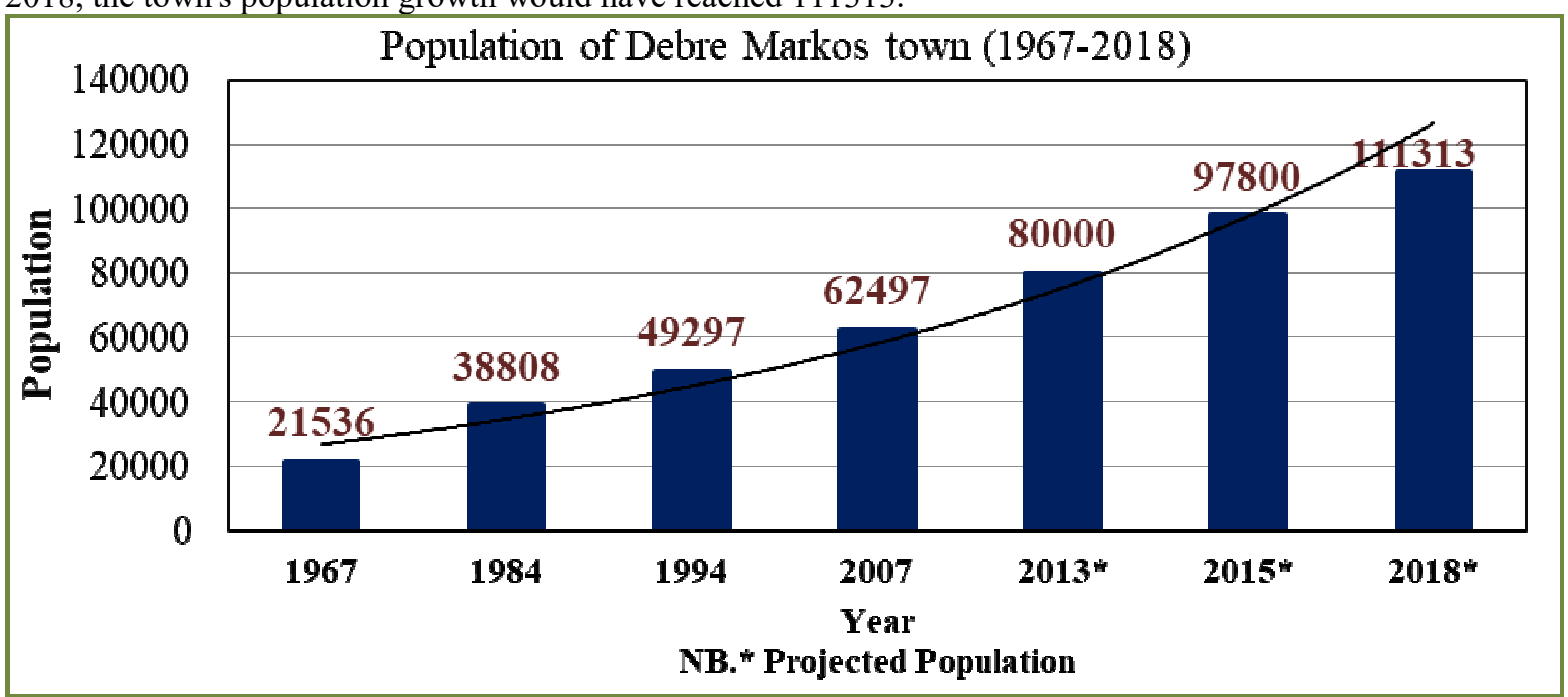

Figure 4: The town's population increment

Source: Computed and analyzed from NUPI, 1998 and CSA, 2007

Migration is one of the basic components of population growth and redistribution, particularly for these areas. It has a direct effect on both receiving and sending areas in conjunction with population growth rate. It affects economic growth, social welfare and the political environment of an area. According to Debre Markos municipality report (2016), migrants in the town accounted for 30.34 percent of the current population and out of all migrants living in the town, 54.9 percent came from rural areas and the rest 45.1 percent from other urban areas.

As population increase in the town, the demand of land for different purposes as well increases. This situation results in diminishing the forest resource and cultivated land that creates other environmental problems at a rapid rate in the town.

\subsubsection{Availability of Infrastructure}

Availability of infrastructure has long been a pulling factor for the creation of Ethiopian cities and towns. However, Debre Markos is a town administration as well as a capital town of East Gojjam zone. Hence, it has 
both town administration and different zonal governmental offices. This leads to consume large amount of land for construction. Because of this, it has different infrastructure especially social infrastructures like school and health centers that pull the people towards the town. In this town there are 17 kindergartens, 23 primary schools, three secondary schools, 13 colleges and one university. In relation to health, there are 1 hospital, 3 health centers and 7 health posts. Due to increasing of their number and large amount of land which they required, these have contributed to aggravate the urban expansion.

\subsubsection{Topography of the Town}

The other reason that aggravated the development of the scattered pattern in the town, in addition to man-made constraints discussed above, the nature of topography. In Debre Markos is considered to be difficult for urban development. Based on the researcher's observation and municipality strategic document (2009), Debre Markos consists of swampy areas, gullies, ridges and escarpments. This natural constraint also leads to the present expansion of the town.

\subsection{Impacts of urban Expansion on Environment}

The conversion of Earth's land surface to urban uses is one of the most irreversible human impacts on the in this town. It hastens the loss of highly productive farmland, affects energy demand, alters the climate, modifies hydrologic cycles, fragments habitats, and reduces biodiversity. Currently, the environmental impacts of urban expansion reach far beyond town. Due to uncontrolled expansion of the town the impact on environment increased from time to time. The cultivated land and wetlands are converted in to build up areas, forest, grass, and soil are highly affected.

\subsubsection{Impacts of Urban Expansion on Forest}

Horizontal expansion and leapfrog development of the town has been endangering and destroying important natural resources. Deforestation was found to be the major effects of Debre Markos town's expansion.

Table 3: The trend of forest coverage of the study area from 2001-2017.

\begin{tabular}{|l|c|c|c|c}
\hline \multirow{2}{*}{ Year } & \multicolumn{2}{|c}{ Name of kebele and forest coverage in hectare } & \multirow{2}{*}{ Total } \\
\cline { 2 - 5 } & Kebele 03 & Kebele 04 & Kebele 07 & \\
\hline Before 2001 & 2.57 & 2.1 & 450.5 & 455.17 \\
\hline $\mathbf{2 0 0 1 - 2 0 0 4}$ & 2.1 & 1.72 & 390.9 & 394.72 \\
\hline $\mathbf{2 0 0 5 - 2 0 0 8}$ & 1.2 & 0.4 & 362.7 & 322.6 \\
\hline $\mathbf{2 0 0 9 - 2 0 1 3}$ & 0.6 & - & 322 & 322.6 \\
\hline $\mathbf{2 0 1 3 - 2 0 1 7}$ & 0.3 & - & 125 & 125.3 \\
\hline
\end{tabular}

Source: East Gojjam Zone Environmental Protection Office Report, 2017

As indicated in table 2, the forest coverage in three kebeles was decreasing. Kebele 07 had the highest forest coverage in the town which includes Yeraba forest. However, Yeraba and other forest areas in kebele 07 were declined enormously.

According to Debre Markos municipality report and East Gojjam Zone Environmental Protection Office Report, (2009), one of the deforested areas found around Debre Markos University with more than 72 hectares for construction purpose. Another deforested area was kebele 03, before 2007 kebele 03 was covered by forest, but after 2007 the forest at Kebele 03 was cleared for residential purpose.

Rapid urban expansion and destructive exploitation of forest has caused serious economic, social and environmental losses having local, national and global implication. In Debere Markos town starting from 2014 up to now, Yeraba forest was cleared by Amhara forest enterprise. The literature also confirms that due to rapid urban expansion primary forests in various part of the world, currently estimated 17 million to 20 million hectares of forest, are being lost every year in developing countries (Allin, 2002).

\subsubsection{Impacts of Urban Expansion on Cultivated Land}

In the presence of urban plan, there is a possibility that urban space expands beyond plan's limit for selforganization due to population increment. According to the 2009 structural plan documents of Debre Markos, it is an increment of 2733.4 hectares of land from 1998 to 2009. This additional land was agricultural land and above 2000 hectares of land for residential purpose.

From 2014 -2017 there were large amount of land distribution for construction of residence by changing agricultural lands and giving compensation for farmers. Around 5854 of urban dwellers were registered and get $200 \mathrm{~m}^{2}$ for each individual. Due to this, totally 1170.8 -hectare agricultural lands will be converted in to residential land and in the future became one part of the town administration.

Generally, the town expands horizontally year to year rather than vertically and consume large tract of rural land. Population growth and the prevailing urban development practice in different urban centers of the town contributed significantly for the rapid horizontal expansion. And this causes the loss of the arable land, and most importantly the loss of the agricultural livelihood of the farmers in the urban fringe of cities/towns. 


\subsubsection{Impacts of Urban Expansion on Wetlands}

According to UNEP (2006), Wetland are land areas that are wet due to a close interaction with water resources and land areas that are flooded regularly that helps vegetation to adapted in saturated soil condition. Wetland is the valuable and multifunctional natural environment of the land cover in the study area and is intervened by human induced activities like settlement. As wetlands are multifunctional natural ecosystem areas, it need to be conserved because they perform vital functions and provide important services.

A wise use and sustainable utilization of wetlands for the benefit of human kind in a way compatible with the maintenance of the natural properties of the ecosystem are important for human life. According to Debre Markos municipality documents in 2007, in three kebeles 63 hectares of wetland and grassland was provided for residential. In addition to this, the two big rivers of the town Wutrin and Wuseta River found near to this area and decreasing year to year.

\subsubsection{Environmental Degradation in the Town}

As it is mentioned earlier, the town of Debre Markos is now rapidly expanding and growing. But this development has brought a heavy burden on the environment in general and on the natural resource in particular. To mention some of them, many quarry sites have been opened in all directions particularly in river banks, hillsides, and escarpments covered with thick bush lands. Due to lack of proper land husbandry deep Gullies are formed in farm lands. Debre Markos was better in vegetation coverage with natural indigenous as well as exotic trees. However, with the expansion of the city and growth of the population the forests including the indigenous species are being removed to meet their demands as well as due to land use change for different urban infrastructure and services. Nowadays, few areas of natural and manmade forests have remained on the ridges, river banks, around old churches, palace, in the compounds of old private houses, schools and recreational parks. Due to those challenges soil erosion has affected more than three- quarter of cultivated land. Urban expansion \& infrastructure development such as road construction with that of other major prevailing problems have drastically reducing the productive potential: vegetation which is vital for the maintenance of the fragile ecosystem is being cleared at an alarming rate (Girma, 2009; Mulualem, 2009; Ziena, 2017).

The horizontal expansion of the town especially towards south, north, north east and west of the town, created another problem that is physical infrastructure provision such as road, water, electricity and construction of drainage lines. According to information obtained from Debre Markos municipality, $84 \%$ of housing units do not have any drainage lines.

The scattered development and horizontal expansion also created another problem that is solid waste disposal. According to a data obtained from Debre Markos municipality beauty and sanitation annual report, $2012,26.9 \%$ of solid wastes dumped on to free pace around the house, $22.4 \%$ use garbage containers, $12 \%$ burn solid waste and $38.7 \%$ dump outside the compound on open spaces.

Waste management at present time is a major environmental problem in Debre Markos town. In many cases, wastes are either not collected or the collected wastes are disposed in an environmentally harmful manner. Waste dumping sites are often a significant source of pollution to ambient air, soil, and water and also a significant risk for human health \& public welfare. Feyera (2005) also conform that, urban expansion has not been accompanied by environmental protection system. Urban waste has been disposed on open spaces; open drains in the road side and holes in the ground are common features of waste disposal particularly in expansion areas. This exposes the dwellers to sanitation related disease and air pollution.

The expansion also has serious impacts on water quality and quantity. With much of infrastructures, parking lots and companies having paved over the countryside, rainwater and snowmelt are unable to soak into the ground and replenish the groundwater aquifers. Urban expansion leads to an increasing imperviousness, which in turn induces more total runoff volume. So urban areas located in flood-prone areas are exposed to increased flood hazard, including inundation and erosion (Jacquin et al. 2008).

\section{CONCLUSION}

Urban expansion has both positive and negative impacts on urban development. It is a way of civilization and engine of development; on the other hand, its consequences affect the urban environment particularly in developing towns like Debre Markos. The town is rapidly expanding into the surrounding rural areas. The study finding reveals that the planed boundary of the town was increasing by from 1992 to 1998 and by from 1998 to 2017. In the year from 1998 to 2017, all land uses of the town showed an increment except forest and agriculture land which was reduced. During eighteen years 5125 hectare of land was included to urban use, among those land uses residential land use took the lions share and this indicates the demand for housing is increasing whereas agricultural and forest land coverage is reduced. Generally, the coverage of the built up area increases from time to time but the coverage for forest and agricultural land is reduced. The main cause for urban expansion of Debere Markos town is high population growth. Other factors for the urban expansion include: availability of different infrastructure, and topographic nature of the town. The driving force of population growth is migration and natural increase through birth. The unexpected expansion of scattered settlement having 
large plot size and the development of incompatible services are endangering and destroying important natural resources and at the same time incurring unnecessary environmental costs. The present extraordinary expansion and scattered expansion also causes damage on fertile farm lands, huge forest areas, wetlands and degradation of the physical environment like that of water soil and air pollution. Generally, Economic growth is a critical goal for every government to accomplish, to enhance way of life and increase the competence of providing goods and services to satisfy human needs and parallel to this, they have to been paid attention to the environmental conservation.

\section{REFERENCES}

1) Abebaw Andarge, (2017): Monitoring the Urban Growth of Debre Markos Town (1984-2012), Ethiopia: Using Satellite Images and GPS; Journal of Geography and Regional Planning Vol. 10(4), Pp. 69-76, April, 2017

2) Achamyeleh Gashu (2014): Peri Urban Land Tenure in Ethiopia; Doctoral Thesis in Real Estate Planning and Land Law Royal Institute of Technology (KTH) Stockholm, Sweden

3) Adem Kedir(2010): Urban Expansion and The Neighborhoods: The Case of Bishoftu Town, East Shewa Zone, Oromia Regional State: Msc. Thesis Addis Ababa University, Addis Ababa, Ethiopia

4) Ahlam Yimam (2017). Urban Expansion and Its Impact on the Livelihood of Peripheral Farming Communities: The Case Of Kutaber Town, Amhara Region, Ethiopia.

5) Bamilaku Amente(2009): Environmental Impacts of Urban Land-Use Changes in Kolfe Keranyio Sub-City, Kebele 04 Selti Area, Addis Ababa Using Remote Sensing and GIS Techniques; Msc. Thesis Addis Ababa University, Addis Ababa, Ethiopia

6) Berke A. (2006): Urban land use planning. Chicago, luliono press

7) Brinn, S and Williams, J. (1983): Cities of the world. World regional urban development, New York.

8) Central Statistical Authority (2007): Federal democratic of Ethiopia central statistical Agency. Annual statistics magazine, Addis Ababa

9) Central Statistical Authority (2013): Federal democratic of Ethiopia central statistical Agency. Annual statistics magazine, Addis Ababa

10) Debela, Diriba \& Azadi, Hossein \& Senbeta, Feyera \& Abebe, Ketema \& Taheri, Fatemeh \& Stellmacher, Till. (2016). Urban sprawl and its impacts on land use change in Central Ethiopia. Urban Forestry \& Urban Greening. 16. 10.1016/j.ufug.2016.02.005.

11) Debre Markos (20 16): Debre Markos municipality annual report (Amharic Version)

12) Debre Markos(20 17): Debre Markos municipality annual report (Amharic Version)

13) Debre Markos(2011): Debre Markos municipality 5years strategic plan (Amharic Version).

14) Dejene Nigusie (2011): Rapid Urban Expansion and Its Implications on Livelihood of Farming Communities on Peri-Urban Area: The Case of Sebeta Town; Msc. Thesis Addis Ababa University, Addis Ababa, Ethiopia

15) Demel, T. 2001. Deforestation Wood and environmental degradation in Ethiopian Highlands Ecosystem, North East Africa Studies.

16) East Gojjam Environmental Protection Office. (2013): East Gojjam Environmental Protection Office annual report (in Amharic Version).

17) Eyasu Shishigu (2007): The Impact of Urban Expansion On the Livelihood of Peri-Urban Farming Communities in Alamgena Town; Msc. Thesis Addis Ababa University, Addis Ababa, Ethiopia

18) Feyera Abdissa (2005): Urban Expansion and The Livelihood of Peri-Urban Areas Agricultural Community: The Case of Addis Ababa: Msc. Thesis Addis Ababa University, Addis Ababa Ethiopia

19) Firew Bekele (2010): The Impact of Horizontal Urban Expansion On Suburban Agricultural Community Livelihood: The Case of Tabor Sub-City, Hawassa City, SNNPRS, Ethiopia: Msc. Thesis Addis Ababa University, Addis Ababa, Ethiopia

20) Getahun Zewdu (2017). The Factors Contributing for the Expansion of Informal Settlements: A Case Study of Haramaya Town, Oromia-Ethiopia

21) Habetamu Belay. (2009): The Founding of Debre Markos Town and its overall Picture Today. Debre Markos.

22) Habtamu Atelaw (2011): The Livelihood of Displaced People in Addis Ababa: In The Case of People Relocated in Arat Kilo Area: Msc. Thesis Addis Ababa University, Addis Ababa, Ethiopia

23) Habtamu Legesse (2011): Challengesof Urban Plan Implementation in Small Towns of Ethiopia: The Case of Gelan Town; Msc. Thesis Addis Ababa University, Addis Ababa, Ethiopia

24) Henok Mengistu (2014): The Impact of Urban Development on Gelan Town; Msc. Thesis Addis Ababa University, Addis Ababa, Ethiopia

25) Hussien Mohamed (2013): Assessment of The Impact of Urban Expansion on the Surrounding Environment of Jijiga City: Somali Region, Msc. Thesis Ethiopian Civil Service University, Addis Ababa, Ethiopia 
26) Kalkidan, T. (2007). Project Proposal on the Construction of Multipurpose Cultural Center in Debre Markos Town. Debre Markos.

27) Langston Graig and Grace Ding. (2001): Sustainable practices in the Built Environment

28) Minwuyelet. (2004): City expansion squatter settlements and policy implication in Addis Ababa; The case of KolfeKeranio sub city, MA Thesis, Addis Ababa; Addis Ababa university.

29) Mulu W. (2016): The Challenges of Current Urban Upgrading Projects in Addis Ababa: A Case Study if Chew Berenda: Msc. Thesis Norwegian University of Technology, Trondheim

30) Muluadam A. (2009); Challenges and Prospects of Rural-Urban Marketing Linkages in Debre Markos Town and Its Hinterland, Amhara Administrative Regional State, Ethiopia

31) Musha. A. (1994): Upraise of the urban planning process. United Nation Centre for Human settlement, Hubiytatli university of Botswana, Governess.

32) NUPI. (1998). National Urban Planning Report on Development Plan of Debre Markos Town.

33) Sewnet M. (2008): Impact of Urban Expansion on Environment: The Case of Debre Markos and Its Surrounding: Unpublished Msc. Thesis Addis Ababa University. Ethiopia

34) Sonar, K. 2008. Urban sprawl. A system Dynamic Approch,44, ISO CARP congress.

35) Tegegne Gebere Egziiabher, 1999. Urban poverty and the environment: illustration from Addis Ababa, in Ethiopia; Ethiopian Development Forum Vol. No. I: 76-84

36) Tersa, H. 1990. Population growth and agricultural productivity. Population growth reproduction in Sub Saharan Africa. The World Bank, Washington D.C in U.S.

37) Thorns, D. 2002. The transformation of cities. Urban theory and urban life. Palgrave Macmillan, New York

38) Tigizaw Lamesgen (2014). The Influence of Urban Expansion on Physical Environment: the case of Debre Markos Town, Amhara Region, Ethiopia. Msc. Thesis Addis Ababa University, Addis Ababa, Ethiopia

39) Tsegaye Tegenu (2010): Urbanization in Ethiopia: Study On Growth, Patterns, Functions and Alternative Policy Strategy: Stockholm University, Stockholm

40) United Nation Population Division. 2007. World urbanization prospects. The 2007 revised, New York, United Nation.

41) Paulos Lukas Thomas Dana (2017). Impact of Urban Expansion on the Livelihood of Peri- Urban Agricultural Community: Case of Wolaita Sodo Town, Southern Ethiopia Civil and Environmental Research ISSN 2224-5790 (Paper) ISSN 2225-0514 (Online) Vol.9, No.2, 2017

42) Yohannis Dukale (2012): Assessment of Urban Plan and Design Implementation and Management in Ethiopian Secondary Towns: The Case of Dilla, MSc. Thesis Addis Ababa University, Addis Ababa, Ethiopia

43) Ziena Lingereh (2017): Mapping Land Use and Land Cover Change and Their Effects on Urban Pre-Urban Agriculture in Debre Markos Town, Ethiopia. MSc. Thesis Addis Ababa University, Addis Ababa, Ethiopia

44) Zipper, A. 2002. Urban influences on forest Ecosystems in human settlement. The southern wild land urban interface assessment. 